\title{
Diastereo- and Enantioselective Conjunctive Cross- Coupling via a Metalate Shift
}

\section{Key words}

palladium catalysis

conjunctive crosscoupling

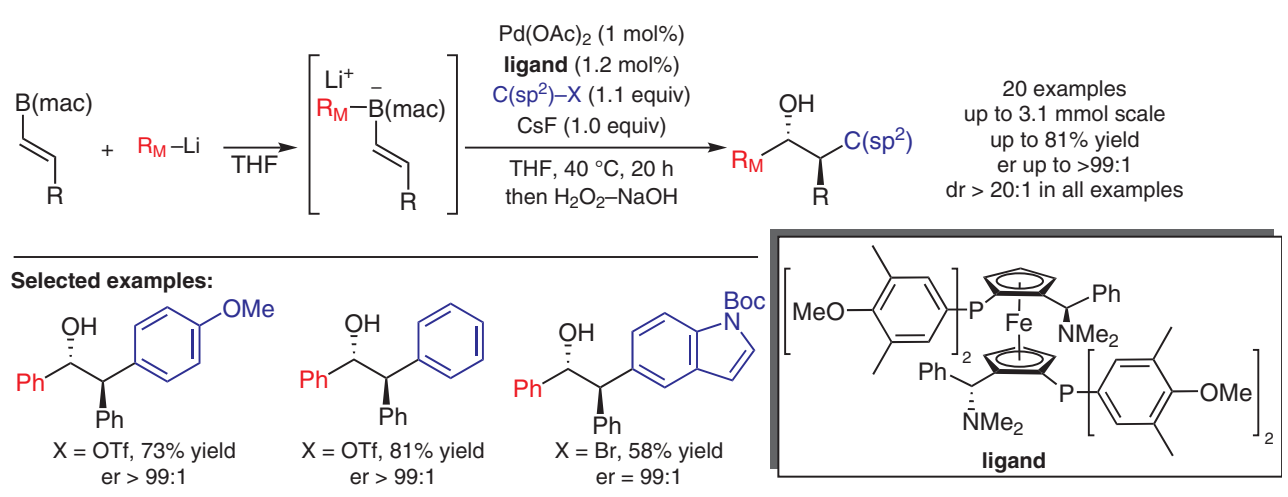

metalate shift
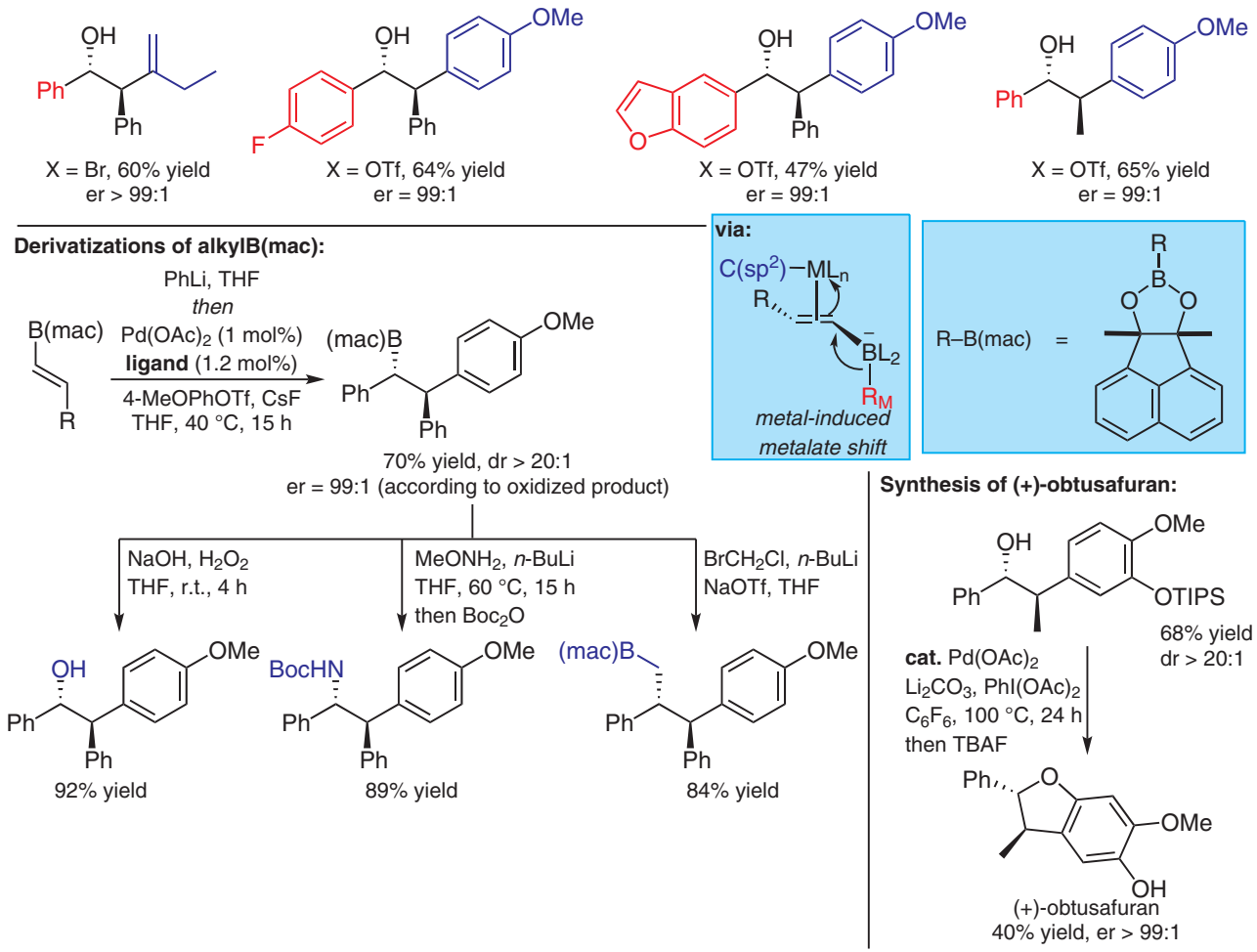

Significance: The authors describe a conjunctive cross-coupling process to access products with vicinal stereogenic centers. This method avoids the generation of Suzuki-Miyaura stilbene byproducts obtained when typical boronic esters are employed.
Comment: Products are obtained in moderate yields and excellent enantio- and diastereoselectivities. The synthetic utility of the $-B(\mathrm{mac})$ handle is demonstrated. Additionally, this methodology was used for the synthesis of $(+)$-obtusafuran. 